\title{
PELAYANAN PUBLIK MELALUI SISTEM E-FILLING DI KANTOR PELAYANAN PAJAK PRATAMA CILEGON
}

\author{
Nurfatma Asriyanti', Arif Nugroho', Racmi Yulianti ${ }^{1}$ \\ ${ }^{1}$ Prodi Administrasi Publik FISIPKUM Universitas Serang Raya \\ Jl. Raya Serang-Cilegon Km.05 (Taman Drangong), Serang-Banten
}

\begin{abstract}
This study aims to determine Public Services through the E-filling System at the Cilegon Primary Tax Service Office and to determine the supporting and inhibiting factors. The research used is descriptive qualitative approach. The data sources used are primary and secondary data. To deepen the data analysis interviews, observation and documentation were carried out. The theoretical basis used is public service. The results showed that the public service through the e-filling system was running well reviewed with the theory of public service. But there are several supporting and inhibiting factors found. Supporting factors 1) employee upgrading, 2) socialization. The inhibiting factors are: 1) lack of human resources, 2) e-fillig applications are down or error
\end{abstract}

Keyword: Services, E-filling, Primary Tax Service Office

\section{Pendahuluan}

Dalam kegiatan pelayanan tidak terlepas dari kehidupan masyarakat, karena pelayanan sangat dibutuhkan di segala aspek kehidupan masyarakat. Masyarakat sebagai pelanggan dari pelayanan publik, memiliki kebutuhan dan harapan pada kinerja penyelenggara pelayanan publik yang profesional. Dengan UU No. 25 Tahun 2009 tentang Pelayanan Publik menegaskan bahwa pentingnya menyediakan pelayanan yang berkualitas bagi masyarakat dalam mengatasi berbagai urusan yang dibutuhkan.

Hal ini merupakan tuntutan bagi instansi pemerintah untuk dapat meningkatkan pelayanan yang terbaik serta untuk dapat melaksanakan tugasnya dengan baik. Pelayaann publik yang kini sudah semakin canggih, kemudian salah satu instansi pemerintah yaitu Diktorat Jendral Pajak membuat hal baru untuk meningkatkan pelayanannya dalam bidang perpajakan yaitu dengan memanfaatkan teknologi, infromasi dan komunikasi, salah satunya aplikasi yang berbasis online dalam sistem perpajakan di Kantor Pelayanan Pajak Pratama Cilegon. Dalam penggunaan e-filling ini juga mengalami peningkatan yang signifikan dalam Pelaporan SPT Orang Pribadi, meningkatkan rasio kepatuhan diiringi dengan jumlah laporan secara elektronik atau online di Tahun 2018. 
Tabel 1.1

Jumlah Wajib Pajak

\begin{tabular}{|l|l|l|}
\hline No. & Wajib Pajak & Jumlah \\
\hline $\mathbf{1}$ & Wajib Pajak Badan & $\mathbf{7 7 9}$ \\
\hline $\mathbf{2}$ & $\begin{array}{l}\text { Wajib Pajak Non } \\
\text { Karyawan }\end{array}$ & $\mathbf{8 5 8}$ \\
\hline $\mathbf{3}$ & $\begin{array}{l}\text { Wajib Pajak Orang } \\
\text { Pribadi }\end{array}$ & $\mathbf{2 0 . 7 3 8}$ \\
\hline & \multicolumn{1}{|c|}{ Total } & $\mathbf{2 2 . 3 7 5}$ \\
\hline
\end{tabular}

Sumber : Bantenraya.com 2018

Berdasarkan data diatas dapat disimpulkan bahwa sistem e-filling merupakan terobosan baru yang memang dapat meningkatkan pelayanan dalam perpajakan yang mempermudah penggunanya dalam pelaporan SPT.

Gambar 1.1

Situs Resmi DJP Online

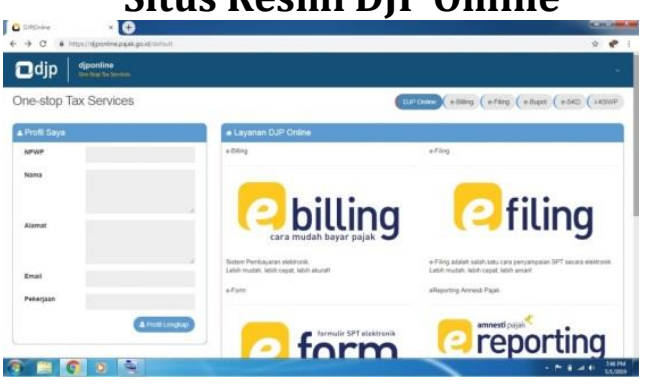

Sumber : Situs DJP Online

Dalam penggunaan sistem $e$ filling terdapat beberapa masalah sehingga dapat menghambat tercapainya suatu tujuan yang sudah ditetapkan, adapun permasalahannya yang akan dijelaskan dibawah ini. Pertama saat ini belum semua wajib pajak menggunakan e-filling karena wajib pajak masih menganggap bahwa penggunaan sistem gadget dalam pelaporan SPT masih membingungkan dan kesulitan dalam prosesnya. Kepala Seksi Pelayanan Kantor Pajak Pratama Cilegon Arif Budiono menilai kesadaran wajib pajak di kota cilegon dalam penyampaian Surat Pemberitahuan
SPT Tahunan Pajak Penghasilan masih sangat rendah (www.radarbanten.co.id diakses pada tanggal 29 April 2019 Pukul 23:58). Hal di karenakan masih banyak wajib pajak yang belum paham tentang penggunaan $e$-filling yang berbasis elektronik, karena melalui masa trasisi dari manual ke sistem elektronik tidak mudah bagi wajib pajak yang mungkin sebagian dari wajib pajak belum mengerti cara pengoperasiannya.

Permasalahan kedua, dalam pelaporan SPT yang dilakukan wajib pajak masih terdapat sistem yang error ketika laporan, hal ini akan menyebabkan keterlambatan pelaporan jika waktunya sudah mendekati batas yang telah ditentukan. Dan ketika dalam kondisi error, wajib pajak akan melaporkan SPT Tahunan secara manual di Kantor Pelayanan Pajak. Hal ini mengakibatkan wajib pajak harus mengantri lebih lama dalam pelaporan. (Sumber : Wajib Pajak yang menggunakan e-filling, Asep Syafaat, 06 April 2019, pukul 14:30, yang bertempat di Terate Udik).

Permasalahan ketiga, masih kurangnya sumber daya manusia di Kantor Pelayanan Pajak Pratama Cilegon dalam pelayanan e-filling ini, hal tersebut sesuai dengan wawancara dengan Kepala Subbagian Umum dan Kepatuhan

Dengan adanya pelayanan $e$ filling yang diterapkan di Kantor Pajak Pratama Cilegon diharapkan masyarakat dapat lebih mudah dan mematuhi perpajakan yang telah berlaku dalam proses pelaporannya menjadi lebih efektif dan efesien.

Berdasarkan latar belakang masalah yang sudah dipaparkan di atas, maka perumusan masalah dalam penelitian ini yaitu: 
1. Bagaimana pelayanan publik melalui sistem e-filling di Kantor Pajak Pratama Cilegon?

2. Apa faktor pendukung dan penghambat dalam melaksanakan pelayanan publik melalui sistem e-filling di Kantor Pelayanan Pajak Pratama Cilegon?

\section{Metode Penelitian}

Penelitian ini menggunakan metode deskriptif pendekatan kualitatif. Adapun teknik sampling yang digunakan Purposive sampling. yang menjadi instrument peneliti itu sendiri. Teknik pengumpulan data menggunakan data primer dan data sekunder. Analisis data menggunakan Miles Humberman dan Saldana.

\section{Hasil Penelitian Dan Pembahasan} Menurut Lijan Poltak Sinambela pelayanan public adalah "setiap kegiatan yang menguntungkan dalam suatu kumpulan atau kesatuan, dan menawarkan kepuasan meskipun hasilnya tidak terikat pada suatu produk secara fisik".

Menurut Sadu Wasistiono (2001:5152) dalam buku Hardiansyah (2011) pelayanan publik adalah pemberian jasa baik oleh pemerintah, pihak swasta atas nama pemerintah ataupun pihak swasta kepada masyarakat, dengan atau tanpa pembayaran guna memenuhi kebutuhan dan atau kepentingan masyarakat. Sedangkan menurut UU No. 25 tahun 2009 Bab 1 pasal 1 ayat 1 pengertian pelayanan publikadalah kegiatan atau rangakaian kegiatan dalam rangka pemenuhan kebutuhan pelayanan sesuai dengan peraturan perundang-undang bagi setiap warga negara dan penduduk atas barang, jasa dan pelayanan administratif yang disediakan oleh penyelenggara pelayanan publik.

Selanjutnya, Fitzsimmons dalam buku Sinambela (2011) berpendapat terdapat lima indikator pelayanan publik yaitu realibility yang ditandai pemberian pelayanan yang tepat dan benar, tangibles yang ditandai dengan penyedia yang memadai sumber daya manusia dan sumber daya lainnya, responsiveness yang ditandai dengan keinginan melayani konsumen dengan cepat, assurance yang ditandai tingkat perhatian terhadap etika dan moral dalam memberikan pelayanan, empaty yang ditandai tingkat kemauan untuk mengetahui keinginan atau kebutuhan konsumen. (Sinambela, 2006:7)

Pembahasan dan analisis dalam penelitian ini peneliti mendapatkan data dan fakta yang didapatkan langsung dari lapangan dan disesuaikan dengan teori yang digunakan peneliti ini menggunakan teori pelayanan public menurut Fritzsimmon dalam buku Sinambela. Menganalisis indikator-indikator dalam pelayanan publik yaitu Tanggibles (Berwujud), Realibility (Kehandalan), Responsiveness (Daya Tanggap), Assurance (Jaminnan), Empaty (Simpati).

Pencarian data dilakukan secara investigasi dimana peneliti mengumpulkan data-data dengan melakukan wawancara kepada pihak informan yang memiliki informan tentang masalah yang diteliti. Datadata tersebut merupakan data yang berkaitan dengan penelitian.

Dekripsi hasil penelitian merupakan suatu data dan fakta yang peneliti peroleh dan didapat langsung dari lapangan, baik berupa observasi (pengamatan), wawancara, dan dokumentasi. Peneliti disesuaikan dengan teori yang ada 
Dimensi tangibles Kantor Pelayanan Pajak Pratama Cilegon sudah memadai dalam hal sarana prasarana yang disediakan contohnya menyediakan kelas pajak bagi masyarakat yang memang ingin belajar untuk mengetahui sistem efilling dan menyiapkan TPT (Tempat Pelayanan Terpadu. Adapun sosialisasi yang dilakukan guna menunjag pelayanan dengan sistem online.

Gambar 4.1

Sarana Kelas Pajak

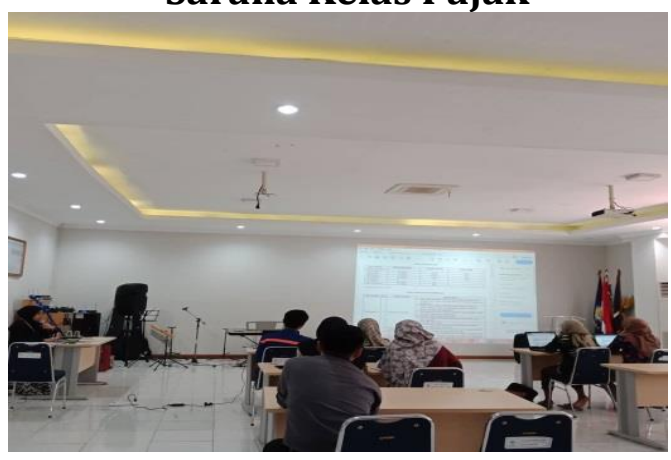

Gambar 4.2

Tempat Pelayanan Terpadu

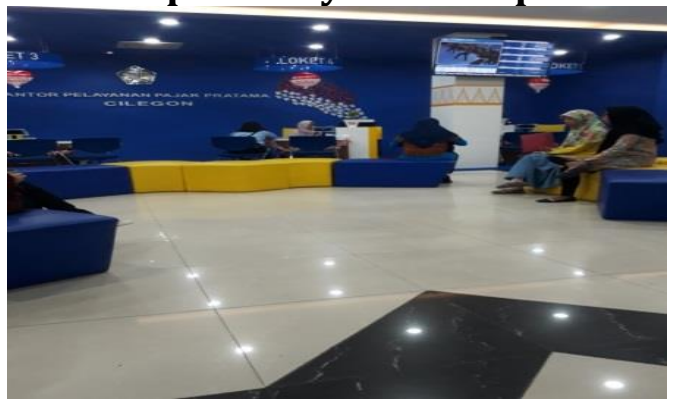

Di samping hal tersebut namun lain hal dengan pengadaan sumber daya manusia yang ada di Kantor Pelayanan Pajak Pratama Cilegon, menurut Bapak Faisal Azkarnaen selaku Kepala Subbagian Umum dan Kepatuhan Internal menyatakan bahwa masalah terkait sumber daya manusia masih kurang pada masa SPT Tahunan karena pada masa itu pelaporan SPT dapat dikatakan sangat banyak yang melaporkan sehingga pelayanan yang diberikan kurang optimal, namun dalam kekurangan SDM tersebut KPP
Cilegon menerapkan upgrading dan pelatihan-pelatihan terhadap pegawai sehinga walaupun dalam sumber daya manusia yang kurang dapat memenuhi seluruh pelayanan.

Dimensi reability. Semakin tingginya kebutuhan msyarakat dalam pelayanan ini perlu diimbangi dengan pelayanan yang maksimal dan cepat yang menuntut aparatur lebih cekatan dalam bekerja. Kehandalam merupakan kemampuan memberikan pelayanan yang dijanjikan dengan cepat, akurat dan memuaskan, seperti halnya dalam kepastian waktu, kecepatan, dan kecermatan. Berdasarkan penelitian yang dilakukan dalam dimensi reability KPP Cilegon dalam menangani segala pelayanan sudah baik. Hal ini ditunjang dari pelatihan pelatihan yang dilakukan oleh KPP salah satunya dengan In House Training

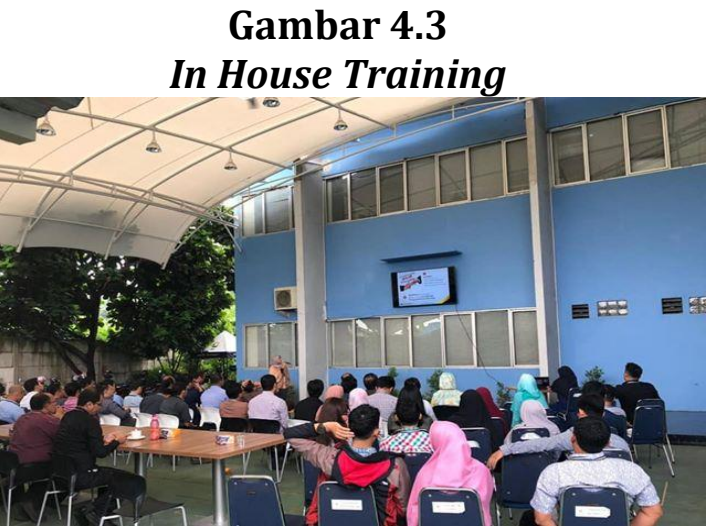

Dimensi Responsiveness sangat diperlukan dalam pelayanan public karena hal ini menjadi bukti serta tindakan nyata yang dilakukan organisasi dalam menjawab serta mengenali kebutuhan dan aspirasi dari masyarakat.

Berdasarkan penelitian yang dilakukan dengan wawancara dapat di tarik kesimpulan bahwa semua pegawai di KPP Cilegon senantiasa selalu bersikap respon kepada masyarakat. Hal ini di ungkapkan juga Bapak Faisal selaku Kepala Subbagian 
Umum dan Internal walaupun jumah sumber daya manusia di KPP Cilegon kurang tetapi selalu mengadakan pelatihan-pelatihan atau upgrading terhadap pegawainya. Dan setiap pegawai juga mengutamakan kebutuhan yang di butuhkan masyarakat hal ini dilihat dari hasil survey yang dilakukan KPP Cilegon dalam bentuk puas dan tidak puas dalam pelayanan perkategori yaitu kecepatan pelayanan, keramahan pelayanan, dan efesiensi pelayanan, sehingga yang dihasilkan adalah ratarata masyarakat merasa puas pada pelayanan yang ada di KPP Cilegon. Hal ini dapat dilihat dalam gambar berikut :

\section{Gambar 4.4}

\section{Diagram Batang Polling Kepuasan} Pelayanan Perkategori

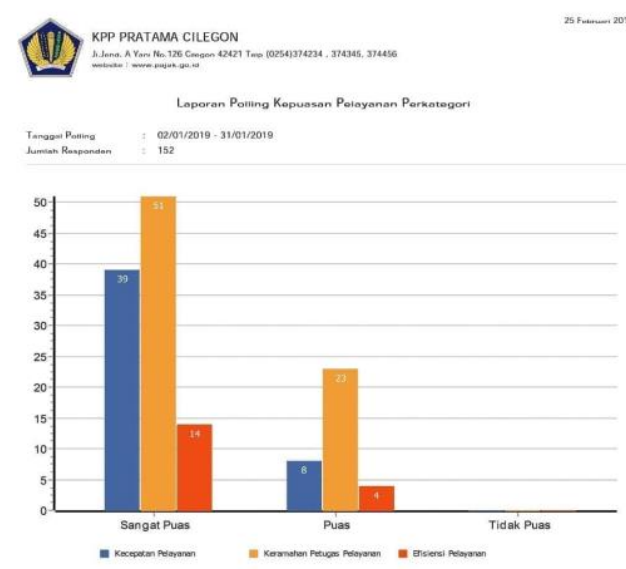

Dimensi Assurance (Jaminan) adalah disetiap bentuk pelayanan memerlukan adanya kepastian atas pelayanan yang diberikan. Bentuk kepastian dari suatu pelayanan sangat di tentukan oleh jaminan dari petugas yang memberikan pelayanan, sehingga orang yeng menerima pelayanan merasa puas dan yakin bahwa segala bentuk urusan pelayanan yang dilakukan akan tuntas dan selesai sesuai dengan kecepatan, ketepatan, kemudahan dan kelancaran yang diberikan.
Berdasarkan hasil dari observasi dan wawancara peneliti dapat ditarik kesimpulan bahwa dalam pelayanan di KPP Cilegon sudah sesuai dengan jaminan waktu yaitu dalam memberikan pelayanan KPP selalu tepat waktu, sesuai dengan waktu yang telah ditentukan, maka dari itu seluruh pelayanan yang dibutuhkan masyrakat dapat terpenuhi dengan cepat dan tepat.

Jaminan atas biaya di KPP Cilegon semua pelayanan manual maupun yang online dilakukan dengan tidak di pungut biaya sama sekali dan itu semua gratis di sediakan oleh dari KPP.

Gambar 4.4

\section{Polling Kepuasan Pelayanan}

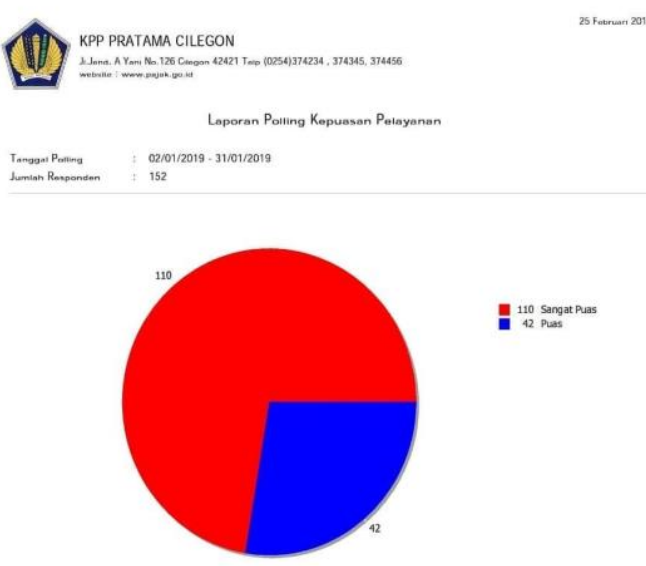

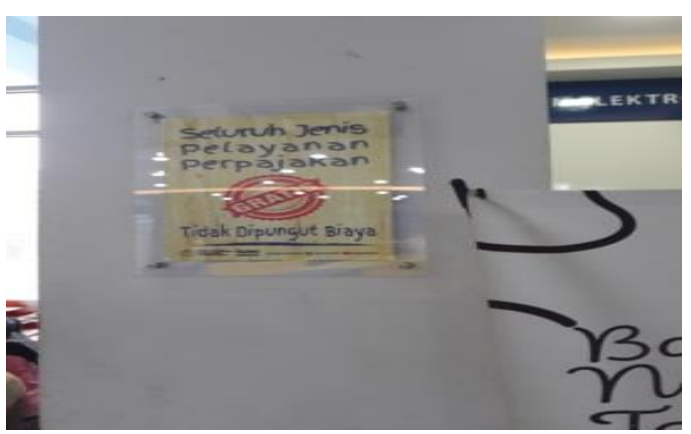

Dimensi Emphaty. Berdasarkan penelitian yang dilakukan dapat di 
simpulkan bahwa dalam pelayanan yang disediakan KPP Cilegon berusaha semaksimal mungkin melayani masyarakat dengan ramah dan sopan hal ini ditunjukan dari pegawai yang cekatan dalam menangani berbagai masalah yang di alami masyarakat terutama dalam pelayanan yang menggunakan sistem online salah satunya e-filling, yang kita ketahui bahwa sistem yang berbasis online jarang sekali masyarakat yang langsung mengerti dalam penggunaannya, maka dari itu pegawai semaksimal mungkin melayani masyarakat yang memang masih ada saja yang kurang paham. Hal ini salah satu upaya pegawai KPP Cilegon dalam memajukan dan meningkatkan pelayanan walaupun dalam jumlah sumber daya manusia yang kurang.

Dalam hal ini juga pegawai dalam melayani tidak deksriminasi terhadap masyarakat, ini di buktikan dalam wawancara dari berbagai sumber dimana menyatakan bahwa dalam pelayanan sesuai dengan prosedur.

\section{Kesimpulan}

Berdasarkan hasil penelitian lapangan yang telah peneliti uraikan maka dapat disimpulkan sebagai berikut :

1. Masih kurang memadai jumlah pegawai di Kantor Pelayanan Pajak Pratama Cilegon pada masa pelaporan SPT Tahunan oleh karena itu KPP mendapatkan bantuan dari mahasiwa/mahasiswi magang yang dikoordinir langsung oleh Kanwil DJP Banten..

2. Pelaksanaan sosialisasi yang kurang intensif oleh Kantor Pelayanan Pajak Pratama Cilegon, ini dibuktikan masih banyaknya masyarakat yang belum mengetahui sistem online ini.

3. Kurangnya koordinasi dan komunikasi Kantor Pelayanan Pajak Pratama Cilegon dengan Diktorat Jendral Pajak Pusat dalam melaksanakan penerapan sistem online salah satuya $e$ filling.

4. Adapun yang menjadi faktor penghambat dan pendukung pelayanan public melalui sistem e-filling. Faktor pendukungnya yaitu dengan adanya upgrading yang dilakukan KPP dapat meningkatkan produktivitas pegawai, dan sosialisasi yang dilakukan. Sedangkan faktor penghambatnya, kurangnya sumber daya manusia pada masa pelaporan SPT Tahunan, aplikasi e-filling yang mengalami down, dan masyarakat yang kurang paham dalam sistem online.

Berdasarkan kesimpulan diatas, maka peneliti dapat memberikan saran sebagai berikut :

1. Ditambahkannya jumlah pegawai di KPP Pratama Cilegon, khususnya di seksi pelayanan perpajakan secara online pada masa pelaopran SPT Tahunan. Hal itu dilakukan agar lebih efektif dan efesien dalam pelayanan secara online.

2. Dilakukannya lagi sosialisasi yang lebih intensif dan berkelanjutan oleh pihak KPP Pratama Cilegon kepada masyarakat mengenai layanan perpajakan secara online sehingga sosialisasi yang dilakukan dapat lebih efektif dan tepat sasaran. 
3. Peningkatan komunuikasi dan koordinasi yang dilakukan antara pihak Kantor Pelayanan Pajak Pratama Cilegon dengan Direktorat Jendral Pajak Pusat dalam rangka menjalin komunikasi dan membahas pelaksanaan sistem pelayanan secara online ini agar lebih baik dalam menangani berbagai hal mengenai pelayanan perpajakan yang dilakukan supaya tidak sistem tidak sering mengalami down ataupun error walaupun banyak yang menggunakannya.

\section{Referensi}

Denhardt, Janet V. dan Robert B. Denhardt. 2003. Pelayanan Publik Baru Dari manajemen Steering Ke Serving. Armonk, New York. M.E.Sharpe.

Inrajit, Richardaus Eko. 2004. Electronic Government. Yogyakarta. ANDI Yogyakarta.

Hardiyansyah. 2011. Kualitas Pelayanan Publik. Yogyakarta. Gava Media

Mukarom, Zaenal. Laksana, Muhibudin Wijaya. 2015. Manajemen Pelayanan Publik. Bandung. CV Pustaka Setia.

Pasolong, Harbani. 2013. Metode Penelitian Administrasi Publik. Bandung. ALFABETA

Sugiyono. 2014. Metode Penelitian Administrasi. Bandung. ALFABETA.

Sugiyono. 2017. Metode Penelitian Kuantitatif, Kualitatif, dan R\&D. Bandung. ALFABETA.
Sinambela, Lijan Poltak. 2008. Reformasi Pelayanan public Teori, Kebijakan, dan Implementasi. Jakarta. PT Bumi Aksara.

Ariyanto, Maulana. 2015. Skripsi. Analisis Pelaksanaan Egovernment Di Kantor Pelayanan Pajak Pratama Serang (studi kasus pada pelayanan e-Registration, e-SPT, dan e-Filling). Universitas Sultan Ageng Tirtayasa.

Astuti, Inne Nidya. Jurnal. Anlisis Penerapan E-Filling Sebagai Upaya Meningkatkan Kepatuhan Wajib Pajak Dalam Penyampaian Sutar Pemberitahuan (SPT) Tahunan Pada Kantor Pelayanan Pajak Pratama Gresik Utara. Universitas Negeri Surabaya.

Darmawan, Dani. 2018. Jurnal. INOVASI SEKTOR PUBLIK DALAM PELAYANAN PEMBAYARAN PAJAK KENDARAAN BERMOTOR KOTA $M A K A S S A R$. Universitas Negeri Makasar.

Etika, Raih. 2017. Jurnal. Analisis Efektifitas Penerapan E-Filling Dalam Pelaporan Surat Pemberitahuan Tahunan Oleh Wajib Pajak Di Kantor Pelayanan Pajak Pratama Kebumen.Universitas Muhammadiyah Yogyakarta.

Meising, Yuyun. J.Sondakh, Jullie. D.L.Warongan, Jessy. Jurnal. Analisis Penerapan E-Filling Pada Wajib Pajak Orang Pribadi Di KPP Pratama Bitung. Universitas Sam Ratulangi. 
http://digilib.uinsby.ac.id/9069/5/b ab3.pdf

Nurhidayat, Sari. 2015. Skripsi. Pengaruh Penerapan Sistem EFilling Terhadap Kepatuhan Wajib Pajak Dengan Pemahaman Internet Sebagai Variabel Pemoderasi Pada KPP Pratama Klaten. Universitas Negeri Yogyakarta.

Wahyuni, Nina. Maesaroh. Jurnal. Analisis Inovasi Pelayanan Di Kepolisian Saerah Jawa Tengah (studi kasus Smile Police). Universitas Diponogoro.

Wilem, Ratag Beny Sujono. Jurnal. Kualitas Pelayanan Publik Di Kantor Kelurahan Ranomut Kecamatan Paal Dua Kota Manado. Universitas Sam Ratulangi.

https://pajak.go.id/electronic-filing diakses pada tanggal 20 April 2019 Pukul 16:15

(www.pajak.go.id) diakses pada tanggal 14 April 2019 Pukul 23:15)

(ekonomi.kompas.com diakses tanggal 15 April Pukul 14:35)

(www.kemenkeu.go.id diakses pada tanggal 15 April 2019 Pukul 16:10)

(www.OnlinePajak id diakses pada tanggal 22 April 2019 Pukul 19:45)

(www.Bantenraya.com diakses pada tanggal 29 April 2019 Pukul 00:50). 